\title{
History of surgery for cerebrovascular disease in children. Part III. Arteriovenous malformations
}

\author{
Jeffrey P. Blount, M.D., R. Shane Tubbs, P.A.-C., Ph.D., W. Jerry OAKes, M.D., \\ AND Robin P. HuMPHREYS, M.D. \\ Division of Pediatric Neurosurgery, University of Alabama at Birmingham/Children's Hospital \\ of Alabama, Birmingham, Alabama; and the Hospital for Sick Children, University of Toronto, \\ Ontario, Canada
}

\begin{abstract}
$\checkmark$ Arteriovenous malformations (AVMs) are the most common cause of intracerebral hemorrhage in children. In this paper the authors trace the historical evolution of the recognition, diagnosis, and treatment of pediatric intracerebral AVMs, and they summarize the contemporary approach and current controversies surrounding treatment of these lesions. Important distinctions between adult and pediatric AVMs are emphasized.
\end{abstract}

\section{KEY WORDS - arteriovenous malformation - pediatric neurosurgery - history of neuro- surgery - children}

\section{Arteriovenous Malformations in Children}

In a recent publication about AVMs in children, Dr. Humphreys ${ }^{24}$ opined that the history of AVMs in children is a microcosm of neurosurgical history ${ }^{25}$ Surgical intervention for pediatric intracerebral AVMs has evolved from initial forays that were undertaken as rescue procedures for critically ill children, performed without the aid of proper lighting or magnification, into a multimodality, multidisciplinary tour de force that couples the greatest advances in interventional neuroradiology with those of cerebrovascular microneurosurgery and stereotactic radiosurgery. Hundreds of articles have been written to address various aspects of these fascinating, challenging, and dangerous lesions in the last 30 to 40 years, yet much remains unknown, and these malformations frequently tax the capabilities of the most skilled and experienced multidisciplinary teams.

\section{Historical Context}

As quoted by French and Chou, ${ }^{17}$ in 1928 Harvey Cushing stated that surgical removal of an AVM was unthinkable. At that time he further noted that no such attempt had ever been made, because even exposure of the lesion brought with it great risk of profound hemorrhage. There certainly was an awareness of a variety of intracranial vascular lesions and their potential for apoplectic, life-threatening hemorrhage. In the absence of capability for successful direct attack, Cushing and others embraced decompressive procedures to deal with the associated elevation in intracranial pressure.

By the mid-twentieth century, a meaningful classifica-

\footnotetext{
Abbreviations used in this paper: $\mathrm{AVM}=$ arteriovenous malformation; $\mathrm{CT}=$ computerized tomography; LINAC = linear accelerator; $\mathrm{MR}=$ magnetic resonance; $\mathrm{SRS}=$ stereotactic radiosurgery.
}

tion of intracranial vascular lesions had evolved and AVMs were recognized as a markedly convoluted mass of arteries and veins in which an intervening capillary bed was absent. ${ }^{46}$ Matson $^{38}$ described them as "localized collections of abnormal vessels of the cerebrum arranged usually in a roughly wedge-shaped mass which has its base on a cortical surface of the hemisphere and its apex projecting inwardly, usually to the subependymal region of the lateral ventricle." It was recognized that these lesions could take on any shape or size, but that they most commonly formed a wedge with its apex at the ventricle. The terms "fibrous" and "gliotic" characterize the brain tissue within the lesion. Other recognized vascular anomalies included the following: 1) cavernous malformation, with its characteristic sinusoidal cavities, berry-like appearance, and limited proclivity toward spontaneous hemorrhage; 2) venous angioma, which represented an enlarged confluence of normal draining vessels; and 3) capillary telangiectasia, which consisted of focal proliferations of thin-walled capillaries and normal brain between these vessels. ${ }^{17,46}$ Setting aside these other lesions, the sole topic of this historical review is the presence and treatment of true AVMs in children.

\section{Management of Pediatric AVMs}

Principles of the management of pediatric AVMs were initially direct extensions of those arising from experience with adult AVMs. As outlined by French and Chou, ${ }^{17}$ and later reiterated by Matson ${ }^{38}$ in the first published report of pediatric AVMs, there was a definable evolution in the therapeutic approach to these lesions. As alluded to earlier, the first phase was external decompression, which involved decompression of the skull and dura mater to alleviate elevated intracranial pressure. Internal decompression followed, and was characterized by efforts to divert the cerebrospinal fluid that built up as a result of impairment to 
normal flow caused by the lesions. Ligation of feeding vessels, first extracranial and then intracranial, was the next conceptual step. Extracranial ligation was directed toward symptomatic relief and reduction of the risk of hemorrhage. External ligation was relatively quickly abandoned when it was realized that surgical reduction of flow potentiated the anoxic impact of the large vascular shunt often associated with AVMs. Intracranial ligation of feeding vessels was the next stage in the evolution of treatment for AVMs. Results were mixed, but the principle of ligation contributed to the development of embolization. Furthermore, greater experience with arterial occlusion led naturally to more aggressive ligation of vessels and in turn to setting the goal of total excision of the AVM. Ultimately the insufficiency of vessel ligation in and of itself led the pioneering neurosurgeon Olivecrona to conclude that total removal was the optimum therapeutic choice for AVMs.

Bergstrand, et al., ${ }^{5}$ originally reported total removal of cerebral AVMs in five patients in 1932. This series was expanded to 24 patients in a later report ${ }^{48}$ from the same group from 1948. Norlen ${ }^{47}$ reported excellent outcomes after total removal of intracerebral AVMs in 10 patients in 1949, and the impact of this report was significant. After this report appeared, neurosurgeons realized the possibility of total removal with good neurological outcome. Over the ensuing 10 to 15 years, corroborative reports by Pool $^{50}$ (total excision in five patients, with good outcome), French and colleagues ${ }^{17,18}$ (82 surgically treated AVMs with a mortality rate of $<10 \%$ ), and Sano ${ }^{51}$ (108 patients) prompted widespread acceptance of the claim that total excision is the preferred modality of treatment.

\section{Early Pediatric Experience: Pediatric Series Before 1990}

Each of the large series of intracerebral AVMs reported in the 1950s and 1960s included small numbers of children, but the first case reports and purely pediatric series appeared in the late 1960s and early 1970s. Seljeskog, et al., ${ }^{53}$ reported successful surgical removal of an AVM involving the inferior sagittal sinus in an infant in 1968, and Moyes $^{41}$ reviewed a small pediatric series of 12 patients with intracranial vascular anomalies in 1969. All 12 presented with hemorrhage and 11 underwent surgery. One patient died but the remainder did well neurologically.

Matson $^{38}$ published the first purely pediatric series of children treated for intracranial AVMs. Between 1952 and 1966, a total of 34 patients with intracerebral AVMs were seen and treated in the pediatric neurosurgical service at the Children's Hospital Boston. Twelve patients underwent total excision, in four evacuation of an associated clot was performed, and 14 were followed up without surgical treatment. Eight of the 14 patients who were followed did well without further problems. There were seven fatal hemorrhages, some of which were the presenting sign of the AVM. Fourteen patients did well after surgical removal of the lesion (one additional patient was included at the end of the series, for a total of 15).

Matson considered the cerebral AVM to be the most common abnormality of the child's intracranial circulation to require the attention of a neurosurgeon, and concluded that direct surgical attack had previously been too risky. Nevertheless, recently available adjuncts such as improved methods of homeostasis, intraoperative hypotension and hypothermia, and the capability to infuse large volumes of blood rapidly and repeatedly have allowed the majority of pediatric AVMs to be directly and safely attacked, with the goal being complete removal.

In 1974, Long, et al., ${ }^{32}$ reported a series of 12 infants with giant cerebral AVMs. Eight of these patients underwent surgery for total removal of the lesion, and six of the eight survived with minimal neurological deficits. An additional insight of this paper relates to the sudden decline in cardiac status that can be precipitated by closure of the fistula. This relates to expanded intravascular volume, which the authors control by "a judicious and measured reduction of blood volume during the exposure" (no blood replacement is done during opening). The second means of controlling for cardiac overload is gradually reducing the size of the fistula. The two deaths occurred after surgery, and all patients who did not undergo the procedure died. These authors concluded that surgical intervention for these lesions when they became symptomatic offered "the best and almost the only chance for successful survival."

In 1980 Mori, et al., ${ }^{40}$ reviewed 28 cases of pediatric AVMs and concluded that intracerebral hemorrhage was a more common presenting symptom in children. They also found higher rates of postoperative morbidity in children. These authors concluded that the prognosis for AVMs in children was worse than that in adults. Kelly, et al. ${ }^{26}$ reported a large pediatric series of intracranial AVMs that were evaluated at the Mayo Clinic in 1978. In this study, 37 patients younger than 20 years of age were evaluated and treated surgically. A mixture of lesions was described. Hemorrhage was again the most common presentation, and surgery was well tolerated.

Gerosa and colleagues ${ }^{20}$ reported results in a large cohort of 56 pediatric patients with AVMs. Thirty-eight of the 56 underwent surgery and 23 attained complete excision. Hemorrhage and seizures were the most common reasons for presentation. Rebleeding before surgery occurred in $29 \%$ of patients with an initial hemorrhage, and carried a poor prognosis. In 23 patients total excision was achieved, and 17 of these were neurologically normal. In 10 patients ligation of feeding branches was performed, and neurological deficits were mixed. Five of 14 patients treated conservatively died. The authors conclude that the outcomes were much better in the surgically treated group.

Celli and colleagues ${ }^{8}$ from the University of Rome contrasted surgical and rebleeding outcomes in children and adults who had undergone excision of an intracerebral AVM. Of 161 patients who were treated between 1951 and 1980, $19(12 \%)$ were 15 years of age or younger. The authors combined these cases with ones presented in the literature, and noted that children suffered worse effects from initial hemorrhage. Furthermore, children had a significantly higher risk of hemorrhage $(\mathrm{p}<0.05)$ over the follow-up period than did adults, particularly if the initial event was nonhemorrhagic. The hemorrhage rate observed by this group of authors for lesions smaller than $2 \mathrm{~cm}$ was greater than $80 \%$.

Eiras, et al., ${ }^{14}$ reported on a group of 15 pediatric patients who underwent surgery for an intracranial AVM. In this report from 1987, subarachnoid hemorrhage was the 
most common presenting sign, and nine of 15 patients who underwent surgery recovered with no new neurological signs.

Ventureyra and Herder $^{62}$ reviewed a large series of 23 children $(<18$ years old $)$ with AVMs who were treated at the Children's Hospital of Eastern Ontario between 1975 and 1985. These authors concur with previous findings in which the high incidence of hemorrhage as a presenting sign of an AVM and the generally favorable outcomes that accompany an aggressive surgical approach are noted. They further conclude that a spontaneous intracerebral hemorrhage in a child is likely to arise from an occult AVM, and they advocate aggressive surgical exploration. Although there is ample evidence of the development of neurointerventional techniques and aggressive surgical exploration in the literature, this is the first large series of pediatric AVMs that directly alludes to adjunctive treatment options beyond open microsurgery.

Fong and Chan $^{16}$ reported on 29 patients under the age of 16 years who suffered from an intracerebral AVM. The patients' age at diagnosis ranged from 1 month to 16 years, and $88 \%$ presented with hemorrhage. All underwent CT scanning and angiographic studies. An important point made by these authors is the potential for late recanalization of a pediatric AVM. In one patient in whom an AVM had been resected, the impression was that total removal had been accomplished. Follow-up angiographic studies obtained 7 years later demonstrated recanalization of the lesion. This case report documents the importance of delayed, repeated angiographic films after resection of a pediatric AVM.

Thus, by the middle to late 1980s, significant experience had been accumulated in the treatment of pediatric intracerebral AVMs. A sufficiently large number of features of these lesions recurred from one series to another to enable important distinctions to be made between pediatric and adult AVMs. These included the generally smaller size and greater propensity to hemorrhage of pediatric AVMs. The natural history of pediatric AVMs had been shown to be worse than that of these lesions in adults. That is, initial hemorrhages characteristically impart more neurological morbidity in children. Pediatric AVMs also had shown a much higher incidence of recanalization after treatment than adult AVMs, and therefore the importance of long-term follow-up review and serial imaging had been established.

Technological advances during this time markedly broadened the indications for and success of surgical intervention for pediatric AVMs. Diagnostically, the development of the CT and MR imaging modalities had proven to be important in understanding the three-dimensional anatomy of these lesions and appreciating the location and extent of associated hemorrhages. Selective techniques in angiography as well as nontoxic, effective contrast materials had been developed that allowed precise definition of feeding arteries and draining veins. Technically, the principles of microsurgery had become widely accepted and served as the cornerstone of rational therapy for cerebral AVMs in adults and children. Magnification and illumination provided by the operating microscope fostered visualization that enabled dissection immediately around the AVM in the surrounding gliotic capsule. Despite the remarkable advance that this represented, there remained a significant percentage of cerebral AVMs that lay beyond the safe capabilities of direct open microsurgery.

\section{From 1990 to the Present}

Technological developments in the early 1990s significantly affected the approach to the treatment of cerebral AVMs. This occurred as a result of the nearly simultaneous development and widespread distribution of stereotactic radiosurgery and advanced endovascular techniques. ${ }^{52,54}$

Stereotactic radiosurgery was developed by Lars Leksell in the mid-1960s, and its early principles were promoted by Steiner in the early 1970s.,34,57,58 Therefore, the longest experience with treatment of cerebral AVMs exceeds four decades. Several radiosurgery modalities are available, including the Gamma Knife (fixed cobalt sources), LINAC, and heavy ion Bragg peak (based on helium ions) methods. Gamma Knife surgery uses 210 ionizing beams of gamma (cobalt) radiation to irradiate the AVM focally. ${ }^{39}$ Precise localization of irradiation can be obtained using isosource planning and calculation.

The first Gamma Knife unit in the US was established in 1987 at the University of Pittsburgh. Shortly thereafter there was a proliferation of units, so that radiosurgical expertise became widely available. The LINAC provides a similar method for delivering focal high-dose radiation in a single session. ${ }^{1,6}$ Precise localization is achieved by isosource shaping and three-dimensional consideration of isosource placement. The exact mechanism by which focused irradiation results in AVM involution remains unknown, but very recent data support the suggestion that radiosurgery induces irreversible cellular damage in the vessel wall and stimulates proliferating smooth-muscle cells there, which in turn may lead to vessel narrowing and occlusion. ${ }^{61}$

Radiosurgery offers several advantages in the treatment of intracerebral AVMs. ${ }^{35,36}$ First, it allows treatment of lesions that may occur in surgically inaccessible areas such as the basal ganglia, thalamus, midbrain, or medulla. Second, the radiation can be delivered as a single dose and requires no incision, with its attendant discomfort and risk of bleeding and need for transfusion. Third, SRS has a high rate of effectiveness, particularly for small AVMs. In the largest reported series in adults, the authors suggested a rate of occlusion of more than $80 \%$ at 12 months and more than $95 \%$ at 2 years posttreatment for small AVMs. Similar rates of AVM involution have been reported in pediatric series.

Radiosurgery also has a number of disadvantages. Most importantly in children, the patient is not protected from another hemorrhage until complete angiographically confirmed obliteration has been achieved. This is particularly important in this group because pediatric AVMs are known to show a higher rate of spontaneous hemorrhage than adult lesions. Complete obliteration has been shown to require a minimum of 12 to 18 months (with higher rates at 24 to 36 months) in many series of AVMs in adults. Therefore, the period of continued risk for an intracranial hemorrhage is longer with radiosurgery than with open surgery. ${ }^{43}$ Second, SRS is significantly less effective for large lesions. Third, the potential for secondary radiation-induced neoplasia must be considered. This is an im- 
portant concern in children, because they should have a longer posttreatment life expectancy than adults, during which they are at risk for secondary neoplasia. Although rare individual cases have occurred, in the radiosurgery literature reports of late radiation-induced neoplasia are remarkably absent. The reason for this is unknown, but is presumed to be due to the highly focused nature of the radiation. Perhaps most importantly, it must be emphasized that the majority of pediatric AVMs will present with a hemorrhage, for which a life-saving acute open operation will prove necessary. Therefore, the role of radiosurgery in pediatric AVMs is likely to be limited to the less common lesions presenting with headache, seizure, or focal neurological deficit.

Several purely pediatric series support the use of radiosurgery in obliterating pediatric intracerebral AVMs. The first purely pediatric series was from Pittsburgh and was reported by Altschuler, et al., ${ }^{2}$ in 1989. In this series, 18 children were treated with Gamma Knife surgery for an intracranial AVM, and there were no neurological changes or other problems at the time of treatment. No child experienced rebleeding during the follow-up period, which ranged from 7 to 19 months. Seven patients with AVMs underwent follow-up angiography at 1 year, and three lesions were noted to be completely obliterated.

Nataf, et al., ${ }^{44}$ used LINAC radiosurgery to treat 57 children who had cerebral AVMs as part of a larger series of 792 patients treated at Saint Anne Hospital in Paris, France, between 1984 and 2000. Follow-up angiograms were available for 49 children $(86 \%)$. Twenty-seven patients underwent other treatment (either embolization or surgery) in conjunction with radiosurgery. The 50 to $70 \%$ isodose ranged from 18 to $28 \mathrm{~Gy}$, and the overall rate of obliteration was $61 \%$. Four patients $(7 \%)$ experienced bleeding after radiosurgery, but no new neurological deficits were found at follow-up review.

Yamamoto, et al., ${ }^{64}$ provided long-term follow up on nine children treated for cerebral AVMs with Gamma Knife surgery. The AVM nidus was completely obliterated in six cases, and the other three demonstrated significant reduction in lesion size. No radiation-induced changes were noted on follow-up MR or CT imaging studies in any patient. Tanaka, et al. ${ }^{59}$ compared responses to Gamma Knife irradiation in adult and pediatric patients who harbored intracranial AVMs. In their study, 70 adults were compared with 23 children. These authors reported that $73 \%$ of the adults and $91 \%$ of the children suffered a hemorrhage as the initial presenting sign. Occlusion of the nidus was observed in $45 \%$ of the adults and $71 \%$ of the children at 1 year, and in 81 and $94 \%$, respectively, at 2 years.

Shin, et al. ${ }^{55}$ published a retrospective review of their experience treating 100 pediatric patients (ages 4 months-19 years) with Gamma Knife surgery at the University of Tokyo Hospital. This series was particularly valuable because of the long follow-up times with angiography. Obliteration rates of 84,89 , and $95 \%$ were observed at 3, 4, and 5 years after treatment, respectively. Four patients demonstrated hemorrhage on neuroimages obtained after radiosurgery, and one patient died of the hemorrhage. The annual bleeding rate was $1.5 \%$. One patient experienced hemorrhage after angiographically doc- umented obliteration of the lesion. This important observation has not been reported after surgical obliteration and raises the very important question whether angiographically confirmed obliteration after SRS confers absolute protection from future hemorrhage.

Levy, et al. ${ }^{31}$ updated the University of Pittsburgh experience with a report in 2000 in which they summarized the outcome in 53 patients treated with SRS for intracerebral AVMs. Thirty-four patients (64\%) presented with at least one hemorrhage. The median AVM volume was $1.7 \mathrm{ml}$, and the mean dose of radiation was $20 \mathrm{~Gy}$. Results were stratified according to groups defined by AVM volume. Levy, et al., achieved obliteration of the lesion in 80\% (28 patients) in Group 1 (AVM $\leq 3 \mathrm{ml}$ ) and in $65 \%$ in Group 2 (AVM 3-10 ml). Four patients experienced hemorrhage after radiosurgery as late as 96 months posttreatment. The authors concluded that the low morbidity and high obliteration rates warrant consideration of radiosurgery as a primary modality of therapy for pediatric AVMs.

Smyth, et al., ${ }^{56}$ reported a series of 40 children with cerebral AVMs who were treated with radiosurgery at the University of California, San Francisco. All patients in this series had at least 36 months of follow up, and the median duration of follow up was 60 months. The mean and median doses of radiation were 16.7 and $18 \mathrm{~Gy}$, respectively. Follow-up angiography was performed in 26 patients and the rest were assessed with MR imaging and/or MR angiography. The overall obliteration rate was $35 \%$, which the authors attributed to the larger size of the AVMs seen at this referral center and to the conservative dosevolume prescriptions delivered in children.

Maity, et al. ${ }^{37}$ reported 17 cases of pediatric AVM treated with SRS at the University of Pennsylvania. Prescribed radiation doses varied from 16 to $18 \mathrm{~Gy}$, and $80 \%$ of the patients received the highest dose. Complete obliteration was demonstrated in $80 \%$ of patients on angiographic studies, but only $53 \%$ demonstrated absence of flow by a combination of angiography, MR imaging, and MR angiography. Four patients experienced delayed complications attributable to radiation (necrosis or vasculopathy).

In a large Italian series of pediatric AVMs in 63 patients treated with Gamma Knife surgery, Nicolato and colleagues ${ }^{45}$ observed a 72 and $77 \%$ rate of obliteration at 3 and 4 years posttreatment, respectively. No bleeding occurred in any patient after SRS and only two patients exhibited radiation-related neurological complications.

The overall role of radiosurgery in children is still being defined. Obliteration rates in most series are approximately 60 to $70 \%$ at 2 to 3 years posttreatment, which means that there is a real risk for repeated hemorrhage in patients treated with radiosurgery. ${ }^{43} \mathrm{Few}$ data have been reported with regard to functional and cognitive outcomes. Nonetheless, a number of studies confirm obliteration for the majority of pediatric patients, and the reported morbidity is very low after SRS.

Contemporary neurointerventional techniques for embolization evolved directly from historical attempts at vessel ligation. Luessenhop and Rosa ${ }^{33}$ first described embolization of AVMs in 1960, as they detailed in their review of earlier cases. There have been significant and consistent improvements in technology since that time that have resulted in better catheters and safer and more permanent embolic materials. ${ }^{13,15,42}$ One of the most important devel- 
opments is the invention of smaller, flow-directed catheters. ${ }^{13}$ This has resulted in a decrease in the number of metal guidewires that are necessary, and there has been a concomitant reduction in embolization-related vascular complications. ${ }^{9}$ A number of embolic agents have been used. Contemporary agents can be broadly divided into solid particles or liquid agents and into absorbable or nonabsorbable materials. Polyvinyl alcohol particles, fibers, microcoils, and silk threads are the solid particles currently in use, whereas liquid agents include $N$-butyl cyanoacrylate and ethylene vinyl alcohol copolymers. ${ }^{12,30}$

One of the early leading treatment centers was in London, Ontario, and was created as a direct extension of the advanced neurovascular service of Dr. Charles Drake. Although they had one of the world's largest experiences with microsurgical treatment of intracerebral AVMs, these investigators realized the inherent limitations of microsurgery and began to investigate alternative methods of treating AVMs. Debrun, et al., ${ }^{10}$ reported successful treatment of 46 adult patients with cerebral AVMs by using bucrylate occlusion or a silastic calibrated leak balloon. Only two of 14 patients treated with the balloon attained complete occlusion, and there were five subarachnoid hemorrhages from vessel injury and one death. The groups treated with bucrylate had more successful outcomes, but complete embolization without surgical intervention was obtained in fewer than half of the patients so treated. In another early adult series, Halbach, et al., ${ }^{23}$ reported on the work directed by Hieshima and Wilson from the University of California, San Francisco. These investigators used detachable balloons in a series of 36 vessel occlusions in 31 adult patients. Despite two new neurological deficits and three dissections in their patients, these authors concluded that balloon occlusion can be a useful adjunct in the treatment of selected AVMs. Other observers have noted that embolization alone is an insufficient treatment for the vast majority of AVMs. Wissoff and Berenstein ${ }^{63}$ commented that "cure is seldom obtained with embolization alone" and Frizzel and Fisher ${ }^{19}$ noted a $5 \%$ rate of cure in a review of published cases in which patients with intracerebral AVMs were treated with embolization alone.

In 1989 Benati, et al., ${ }^{4}$ reported the successful use of Polylene thread embolization as a preoperative adjunct in a series of 11 adult patients. Guo, et al.,22 from the Karolinska Institute in Stockholm, reported the combined use of embolization techniques and radiosurgery in a series of 46 patients with intracerebral AVMs. In 28 patients the size or grade of the AVM decreased after embolization, and 19 of 35 large, high-grade AVMs were treatable by radiosurgery after being reduced in size by embolization. During the mid-1990s, there was a sizable number of publications in which multimodality therapy for adults or mixed series with intracerebral AVMs was embraced. ${ }^{11,21,29,60}$ Pediatric series are notably few; $;, 12,49$ one of the reasons for this may be that the size of pediatric AVMs (and the parent vessel) is typically small, and therefore the vessels may not be optimal for even the finest of subselective catheters. One important exception is the study by Caldarelli and colleagues, who reviewed 39 pediatric patients treated with embolization and either surgery or radiosurgery for an intracerebral AVM. In their practice they contend that microsurgery remains the optimal treatment, but the other modalities are used as adjuncts either to make surgery safer or possible. Embolization alone rarely if ever results in cure, but can be extremely useful in reducing the size of large lesions or eliminating deep feeding arteries that may make surgery more difficult or dangerous. More recent series have suggested reduced rates of complications, which now approximate $10 \%$ with greater experience..$^{30}$

Two very large reviews published after 1990 complete this survey of published series of pediatric intracranial AVMs. Lasjaunias, et al., ${ }^{28}$ reported a retrospective review of 179 cerebral AVMs in children in 1995. This group from Le Kremlin-Bicêtre, France, has the world's largest experience with use of endovascular techniques to treat cerebral AVMs. Bucrylate occlusion is performed via selective cerebral catheterization in preference to open microsurgery. Seventy seven vein of Galen aneurysmal malformations and 102 pial AVMs were treated. Groups were established according to the extent of treatment. Fifteen of 28 patients who harbored pial AVMs in which embolization was complete demonstrated no neurological deficits, whereas death occurred in five. Three patients had transient neurological impairment and two had permanent neurological change. Thirteen patients who had undergone partial embolization later were treated with open surgery. Three patients were treated with SRS after partial embolization. Although it is clear that this group of physicians has a huge experience, it remains difficult to draw firm conclusions from the data presented in this report.

In 1996, Humphreys and colleagues ${ }^{25}$ reported a retrospective 45-year review and analysis of treatment in 160 children harboring intracerebral AVMs. This report followed up and extended the observations of Kondziolka, et al., ${ }^{27}$ who reported a $53 \%$ rate of total excision. Outcomes over the study interval improved significantly and the authors drew a number of important conclusions. Eighty percent of children with these malformations present with hemorrhage, and AVMs remain the most common source of hemorrhagic stroke in children (four times as common as an aneurysm over the same time interval). Most hemorrhages occurred during clinical periods of quietude. Over the study interval virtually no intracerebral AVMs or aneurysms were incidentally discovered (despite 15,000 cerebral arteriograms performed for a variety of clinical indications). Prompt and complete removal of the lesion is the goal in all cases. Large, complex, "thirsty" AVMs are unusual. A decline in the overall mortality rate was observed over the duration of the review as well. The overall mortality rate observed was $12.5 \%$, which decreased over the study interval. These authors cautiously embrace embolization as a potentially useful adjunct to precede excision of the malformation.

\section{Current Management}

Contemporary management embraces multiple modalities of treatment and there is a wide variety of options for care of children harboring an intracerebral AVM. The challenge is in patient selection; that is, which patients will ultimately be best served by surgery or microsurgery with or without embolization compared with SRS with or without embolization. It is evident that this view is overly simplistic, because optimal care will unequivocally feature contributions from each modality, and it is likely that 
the modalities will come to be used in combination. Yet it is also overly simplistic and avoids the responsibility of careful review to assume that every patient will be best treated by a combination of therapies. Complete excision remains the gold standard of treatment if it can be performed with acceptable rates of morbidity. Because the vast majority of children present with hemorrhage, a surgical intervention is more frequently necessary to preserve life or neurological function in this group than in adults. Each modality of treatment has attributes and important potential contributions, but also carries a real risk to the life and well being of the patient.

It is highly unlikely that every patient will require or benefit from every modality. The literature remains incomplete and at present there are no prospective well-controlled trials in progress for careful study of children with intracerebral AVMs. Such trials, although methodologically appealing, are notoriously expensive, time-consuming, and difficult to complete for surgical interventions. It is therefore probable that continued careful and individualized decision making based on the best available data with comprehensive long-term follow up from a diverse group of pediatric neurovascular centers will continue to refine treatment for children harboring intracerebral AVMs.

\section{References}

1. Alexander E III, Loeffler JS: Radiosurgery using a modified linear accelerator. Neurosurg Clin N Am 3:167-190, 1992

2. Altschuler EM, Lunsford LD, Coffey RJ, et al: Gamma knife radiosurgery for intracranial arteriovenous malformations in childhood and adolescence. Pediatr Neurosci 15:53-61, 1989

3. Ammar A: Lars Leksell's vision-radiosurgery. Acta Neurochir Suppl 62:1-4, 1994

4. Benati A, Beltramello A, Colombari R, et al: Preoperative embolization of arteriovenous malformations with polylene threads: techniques with wing microcatheter and pathologic results. AJNR Am J Neuroradiol 10:579-586, 1989

5. Bergstrand $\mathrm{H}$, Olivecrona $\mathrm{H}$, Tonnis $\mathrm{W}$ : Gefaßmißbildungen und Gefaßgeschwulste des Gehirns. Leipzig: Thieme, 1936

6. Betti OO, Munari C, Rosler R: Stereotactic radiosurgery with the linear accelerator: treatment of arteriovenous malformations. Neurosurgery 24:311-321, 1989

7. Caldarelli M, Di Rocco C, Iannelli A, et al: Combined management of intracranial vascular malformations in children. J Neurosurg Sci 41:315-324, 1997

8. Celli P, Ferrante L, Palma L, et al: Cerebral arteriovenous malformations in children. Clinical features and outcome of treatment in children and in adults. Surg Neurol 22:43-49, 1984

9. Coubes P, Humbertclaude V, Rodesch G, et al: Total endovascular occlusion of a giant direct arteriovenous fistula in the posterior fossa in a case of Rendu-Osler-Weber disease. Childs Nerv Syst 12:785-788, 1996

10. Debrun G, Viñuela F, Fox A, et al: Embolization of cerebral arteriovenous malformations with bucrylate. Experience in 46 cases. J Neurosurg 56:615-627, 1982

11. Deruty R, Pelissou-Guyotat I, Amat D, et al: Multidisciplinary treatment of cerebral arteriovenous malformations. Neurol Res 17:169-177, 1995

12. Di Rocco C, Tamburrini G, Rollo M: Cerebral arteriovenous malformations in children. Acta Neurochir 142:145-158, 2000

13. Doerfler A, Goericke S, Wanke I, et al: Flow-directed microcatheters for cerebral embolizations using Ethibloc_-an in vitro study. Neuroradiology 43:1112-1117, 2001

14. Eiras J, Gómez-Perún J, Carcavilla LI, et al: Surgical experience with arteriovenous malformations in children. Childs Nerv Syst 3:156-160, 1987

15. Ezura M, Takahashi A, Yoshimoto T, et al: Hydrophilic polymer-coated guide wire combined with progressive suppleness pursil catheter for safer, more definitive embolization of arteriovenous malformations. Neuroradiology 36:326-329, 1994

16. Fong D, Chan ST: Arteriovenous malformation in children. Childs Nerv Syst 4:199-203, 1988

17. French L, Chou SN: Conventional methods of treating intracranial arteriovenous malformations. Prog Neurol Surg 3: 274-319, 1969

18. French L, Chou SN, Story J: Cerebrovascular malformations. Clin Neurosurg 14:171-182, 1964

19. Frizzel RT, Fisher WS III: Cure, morbidity, and mortality associated with embolization of brain arteriovenous malformations: a review of 1246 patients in 32 series over a 35-year period. Neurosurgery 37:1031-1040, 1995

20. Gerosa MA, Cappellotto P, Licata C, et al: Cerebral arteriovenous malformations in children (56 cases). Childs Brain 8: 356-371, 1981

21. Gobin YP, Laurent A, Merienne L, et al: Treatment of brain arteriovenous malformations by embolization and radiosurgery. J Neurosurg 85:19-28, 1996

22. Guo WY, Lindquist C, Karlsson B, et al: Gamma knife surgery of cerebral arteriovenous malformations: serial MR imaging studies after radiosurgery. Int J Radiat Oncol Biol Phys 25: 315-323, 1993

23. Halbach VV, Dowd CF, Higashida RT, et al: Endovascular treatment of mural-type vein of Galen malformations. J Neurosurg 88:74-80, 1998

24. Humphreys R: Arteriovenous malformations: surgical treatment, in Albright AL, Pollack I, Adelson P (eds): Principles and Practice of Pediatric Neurosurgery, ed 2. New York: Thieme, 2006 (In press)

25. Humphreys RP, Hoffman HJ, Drake JM, et al: Choices in the 1990 s for the management of pediatric cerebral arteriovenous malformations. Pediatr Neurosurg 25:277-285, 1996

26. Kelly JJ, Mellinger JF, Sundt TM Jr: Intracranial arteriovenous malformations in childhood. Ann Neurol 3:338-343, 1978

27. Kondziolka D, Humphreys RP, Hoffman HJ, et al: Arteriovenous malformations of the brain in children: a forty year experience. Can J Neurol Sci 19:40-45, 1992

28. Lasjaunias P, Hui F, Zerah M, et al: Cerebral arteriovenous malformations in children. Management of 179 consecutive cases and review of the literature. Childs Nerv Syst 11:66-79, 1995

29. Lawton MT, Hamilton MG, Spetzler RF: Multimodality treatment of deep arteriovenous malformations: thalamus, basal ganglia, and brain stem. Neurosurgery 37:29-36, 1995

30. Ledezma CJ, Hoh BL, Carter BS, et al: Complications of cerebral arteriovenous malformation embolization: multivariate analysis of predictive factors. Neurosurgery 58:602-611, 2006

31. Levy EI, Niranjan A, Thompson TP, et al: Radiosurgery for childhood intracranial arteriovenous malformations. Neurosurgery 47:834-842, 2000

32. Long DM, Seljeskog EL, Chou SN, et al: Giant arteriovenous malformations of infancy and childhood. J Neurosurg 40: 304-312, 1974

33. Luessenhop AJ, Rosa L: Cerebral arteriovenous malformations. Indications for and results of surgery and the role of intravascular techniques. J Neurosurg 60:14-22, 1984

34. Lunsford LD: Lars Leksell. Notes at the side of a raconteur. Stereotact Funct Neurosurg 67:153-168, 1996/1997

35. Lunsford LD: Radiosurgery as a future part of neurosurgery. Mayo Clin Proc 74:101-103, 1999

36. Lunsford LD, Kondziolka D, Bissonette DJ, et al: Stereotactic radiosurgery of brain vascular malformations. Neurosurg Clin N Am 3:79-98, 1992

37. Maity A, Shu HK, Tan JE, et al: Treatment of pediatric intracranial arteriovenous malformations with linear-accelerator-based 
stereotactic radiosurgery: the University of Pennsylvania experience. Pediatr Neurosurg 40:207-214, 2004

38. Matson DD: Arteriovenous malformations, in Neurosurgery of Infancy and Childhood, ed 2. Springfield, IL: Charles C Thomas, 1969, pp 749-772

39. Mehta MP: The physical, biologic, and clinical basis of radiosurgery. Curr Probl Cancer 19:265-329, 1995

40. Mori K, Murata T, Hashimoto N, et al: Clinical analysis of arteriovenous malformations in children. Childs Brain 6:13-25, 1980

41. Moyes PD: Intracranial and intraspinal vascular anomalies in children. J Neurosurg 31:271-278, 1969

42. Mullan S, Kawanaga H, Patronas NJ: Microvascular embolization of cerebral arteriovenous malformations. A technical variation. J Neurosurg 51:621-627, 1979

43. Nataf F, Ghossoub M, Schlienger M, et al: Bleeding after radiosurgery for cerebral arteriovenous malformations. Neurosurgery 55:298-306, 2004

44. Nataf F, Schlienger M, Lefkopoulos D, et al: Radiosurgery of cerebral arteriovenous malformations in children: a series of 57 cases. Int J Radiat Oncol Biol Phys 57:184-195, 2003

45. Nicolato A, Foroni R, Seghedoni A, et al: Leksell gamma knife radiosurgery for cerebral arteriovenous malformations in pediatric patients. Childs Nerv Syst 21:301-307, 2005

46. Noran HH: Intracranial vascular tumors and malformations. Arch Pathol 39:393-416, 1945

47. Norlen G: Arteriovenous aneurysms of the brain: report of ten cases of total removal of the lesion. J Neurosurg 6:475-494, 1949

48. Olivecrona H, Riives J: Arteriovenous aneurysms of the brain. Their diagnosis and treatment. Arch Neurol Psychiatry 59: 567-602, 1948

49. Perini S, Zampieri P, Rosta L, et al: Endovascular treatment of pial AVMs: technical options, indications and limits in pediatric age patients. J Neurosurg Sci 41:325-330, 1997

50. Pool J: Treatment of arteriovenous malformations of the cerebral hemispheres. J Neurosurg 19:136-141, 1962

51. Sano K: Intracranial arterio-venous malformation with special reference to its treatment. No To Shinkei 17:360-364, 1965

52. Scialfa G, Vaghi A, Valsecchi F, et al: Neuroradiological treatment of carotid and vertebral fistulas and intracavernous aneurysms. Technical problems and results. Neuroradiology 24: 13-25, 1982

53. Seljeskog EL, Rogers HM, French LA: Arteriovenous malformation involving the inferior sagittal sinus in an infant. Case report. J Neurosurg 29:623-628, 1968
54. Setton A, Berenstein A: Interventional neuroradiology. Curr Opin Neurol Neurosurg 5:870-880, 1992

55. Shin M, Kawamoto S, Kurita H, et al: Retrospective analysis of a 10-year experience of stereotactic radio surgery for arteriovenous malformations in children and adolescents. J Neurosurg 97:779-784, 2002

56. Smyth MD, Sneed PK, Ciricillo SF, et al: Stereotactic radiosurgery for pediatric intracranial arteriovenous malformations: the University of California at San Francisco experience. J Neurosurg 97:48-55, 2002

57. Steiner L, Leksell L, Forster DM, et al: Stereotactic radiosurgery in intracranial arterio-venous malformations. Acta Neurochir Suppl 21:195-209, 1974

58. Steiner L, Lindquist C, Adler JR, et al: Clinical outcome of radiosurgery for cerebral arteriovenous malformations. J Neurosurg 77:1-8, 1992

59. Tanaka T, Kobayashi T, Kida Y, , et al: Comparison between adult and pediatric arteriovenous malformations treated by Gamma Knife radiosurgery. Stereotact Funct Neurosurg 66 (Suppl): 1288-1295, 1996

60. Tew JM Jr, Lewis AI, Reichert KW: Management strategies and surgical techniques for deep-seated supratentorial arteriovenous malformations. Neurosurgery 36:1065-1072, 1995

61. Tu J, Stoodley MA, Morgan MK, et al: Responses of arteriovenous malformations to radiosurgery: ultrastructural changes. Neurosurgery 58:749-758, 2006

62. Ventureyra ECG, Herder S: Arteriovenous malformations of the brain in children. Childs Nerv Syst 3:12-18, 1987

63. Wisoff $\mathrm{J}$, Berenstein A: Interventional neuroradiology, in Edwards MS, Hoffman HJ (eds): Cerebral Vascular Disease in Children and Adults. Baltimore: Williams \& Wilkins, 1989, pp 139-158

64. Yamamoto M, Jimbo M, Ide M, et al: Long-term follow-up of radiosurgically treated arteriovenous malformations in children: report of nine cases. Surg Neurol 38:95-100, 1992

Manuscript received May 4, 2006.

Accepted in final form May 11, 2006.

Address reprint requests to: Jeffrey P. Blount, M.D., Pediatric Neurosurgery, Children's Hospital of Alabama, ACC 400, 1600 Seventh Avenue South, Birmingham, Alabama 35233. email: jeffrey.blount@ccc.uab.edu. 